\title{
Improvement of Mechanical Properties of an Aluminum Alloy 7075 by Adding Reduced Graphene Oxide Trough Mechanical Milling
}

\author{
E Cuadros-Lugo ${ }^{1}$, I Estrada-Guel ${ }^{1}, \mathrm{JM}$ Herrera-Ramírez ${ }^{1}, \mathrm{C}$ López-Meléndez ${ }^{2}$ and C Carreño- \\ Gallardo $^{1^{*}}$ \\ ${ }^{1 .}$ Centro de Investigación en Materiales Avanzados (CIMAV). Laboratorio Nacional de Nanotecnología. \\ Miguel de Cervantes No. 120, Chihuahua, Chih., México. \\ 2. Universidad La Salle Chihuahua, Prol. Lomas de Majalca No. 11201, Chihuahua, México. \\ * Corresponding author: caleb.carreno@cimav.edu.mx
}

Nowadays composite materials have a great area of interest due to their physical, chemical, thermal and mechanic properties compared to the materials obtained through conventional methods of fabrication. A composite material is the union of two materials with a remarkable difference of their properties, these materials are mostly considered by a material (matrix) surrounded by fibers or particles of higher stiffens (reinforcer).

It has been reported that graphene (GPN) have a high fracture resistance of $125 \mathrm{GPa}$ which make it an excellent option as a reinforcer [1]. A probe of this can be seen by the addition of graphene into an Al6061 alloy matrix trough mechanical milling and hot pressing that shown an increment of $47 \%$ of tensile resistant compared to the Al-6061 alloy without graphene addition [2]. Also, graphene shows a high adherence into an aluminum matrix due to his high surface area [3]. Another kind of interaction between a copper metal matrix and adding graphene by mechanical milling has been seen in which the graphene tends to be distributed in the grain boundaries [4].

By previous experiments in the laboratory, it could be found that an addition between 0.3 and $0.8 \mathrm{wt} \%$ of GPN into an Al-7075 alloy matrix shows a good improvement of the mechanical properties $\left(\sigma_{\mathrm{y}}, \sigma_{\max } \&\right.$ hardness). Once knowing that after the compressive tests of the composites a tested billet of the Al7075 with $0.3 \mathrm{wt} \%$ of GPN was taken to prepare a sample by FIB and then to be analyzed by TEM to find the interaction between the GPN and the Al-7075 matrix.

Figure 1, shows how the addition of $0.3 \mathrm{wt} \%$ of GPN is compared to a non-addition of graphene into the Al-7075 matrix in which we can see an improvement on the yield strength from $387.27 \mathrm{MPa}$ to 405.82 $\mathrm{MPa}$ immediately by just adding the graphene to the matrix. Also, a major percent of strain can be observed as an effect of the $0.3 \mathrm{wt} \%$ of GPN on the matrix.

In figure 2 (a) can be seen how graphene is distributed on the grain boundary as previously mentioned, this can be attributed to the mechanical milling process in which the graphene tends to a cold-welding process to the surface of the Al-7075 particles. Figure 2 (b) is a clear example of how the grain boundaries stop dislocations and also graphene can contribute to a reinforcement of the grain boundaries $[5]$. 


\section{References:}

[1] J Wang et al., Scripta Materialia 66 (2012), p. 594.

[2] M Bastwros et al., Composites: Part B 60 (2014), p. 111.

[3] SJ Yan et al., Materials Science \& Engineering A 612 (2014), p. 440.

[4] C Salvo et al., Journal of Alloys and Compounds, Volume 777 (2019), p. 309.

[5] The authors acknowledge to the Red Temática Nacional de Aeronáutica, Red Materiales Compuestos and Red Temática de Nanociencias y Nanotecnología (152992).

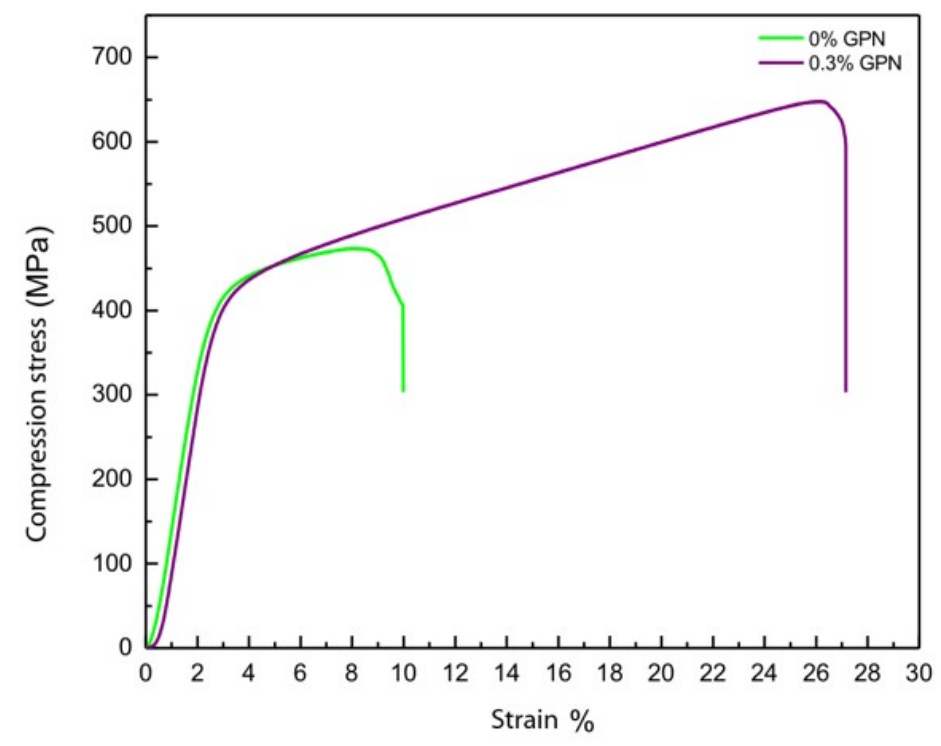

Figure 1. Room temperature compression stress strain compression curves of $0.0 \mathrm{wt} . \%$ and $0.3 \mathrm{wt} . \%$ GPN.
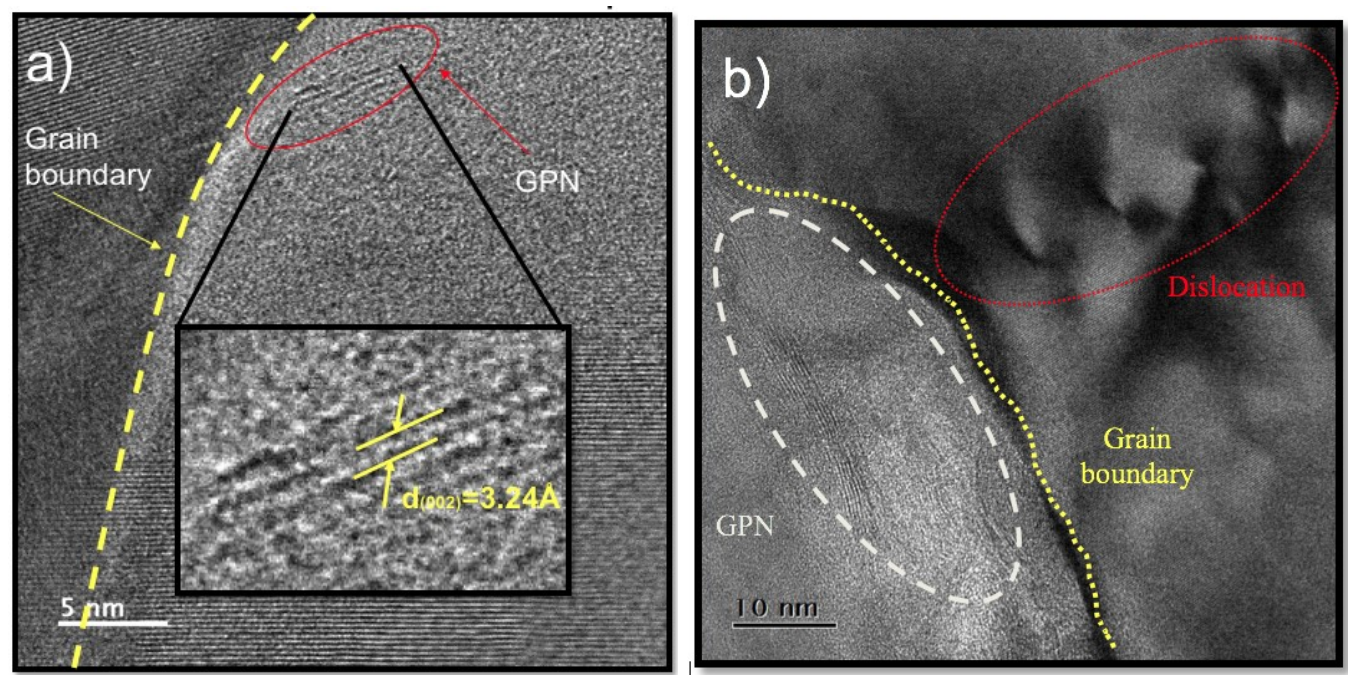

Figure 2. The interaction between graphene, grain boundary, and dislocation. 